\title{
Una reivindicación de la enseñanza de la historia y la geografía de tipo nacional en el contexto del nuevo (des)orden educativo mundial
}

\section{A discourse in favor of History and Geography teaching of national kind in the context of the new educational (dis)order}

\author{
Renán Vega Cantor
}

\section{Resumen}

En este ensayo se examinan ciertos aspectos referidos a la enseñanza de la historia y de la geografía en el contexto actual. Para ello se presenta una reflexión sobre tres aspectos: en primer lugar, se consideran algunas de las características del "nuevo (des)orden educativo mundial"; en segundo lugar, se analiza el impacto de las transformaciones educativas sobre las ciencias sociales escolares; $y$, en tercer lugar, se reivindica la importancia de la enseñanza de una historia y de una geografía de tipo nacional, como parte de un proyecto encaminado a recuperar una perspectiva crítica en los saberes escolares que pueda servir a los estudiantes de nuestro tiempo y como alternativa a unas etéreas ciencias sociales escolares, las cuales han ido imponiéndose en el sistema educativo colombiano.

\section{Palabras clave:}

Enseñanza de la historia y la geografía, conocimiento escolar, (des)orden educativo mundial, pensamiento crítico.

\section{Abstract}

In this paper certain aspects related to the teaching of Histoy and Geography are examined in the current context. For this purpose, a reflexion about three topics is presented. In the first place, some characteristics of the new educative global (dis)order are considered. Sencondly, the impact of educative transformations on school social sciences is analyzed. Finally, a nationalistic approach to the teaching History and Geography is proposed, as part of a general project directed to the recovery of a critical point of view for school kwnowledge. This approach could serve students of our times to be in touch with a way of thinking alternative to the etherial school social sciences that have been imposed in Colombian educational system.

\section{Key words:}

Teaching of History and Geography, school knowledge, global educative (dis)order, critical thinking.

* Profesor Titular de la Universidad Pedagógica Nacional. Autor de libros y ensayos sobre historia de Colombia, enseñanza de la historia, economía y crítica social, entre ellos Historia: conocimiento y enseñanza. La cultura popular y la historia oral en el medio escolar, Editorial Antropos, Bogotá, 1999; Gente muy Rebelde, 4 Volúmenes, Ediciones Pensamiento Crítico, Bogotá, 2002; Los economistas neoliberales: nuevos criminales de guerra. El genocidio económico y social del capitalismo contemporáneo, Centro Bolivariano, Caracas, 2005. rvega@pedagogica.edu.co 
Es necesario rehabilitar la geografía y la historia dentro de los aparatos educativos, propiciando el máximo protagonismo posible y argumentando su funcionalidad directa. La geografía y la historia pueden y deben convertirse en los ejes estructurantes que permitan la integración de las demás ciencias sociales $(\ldots)$

La geografía y la historia están hoy en una nueva encrucijada. Durante decenios han sido utilizadas en la escuela como instrumento de brutalización ideológica. Ahora, tenemos la oportunidad de reconvertir la funcionalidad de esas materias al servicio de la racionalidad, el relativismo, la solidaridad y la cultura democrática. $L a$ responsabilidad de los docentes en ese proceso no es poca. No solo somos útiles; somos más que necesarios, somos imprescindibles.

F. Xavier Hernández, La enseñanza de las ciencias sociales. Balance y perspectivas. En Educación y Cultura 47, agosto de 1998, pp. 21-22.

\section{Las transformaciones forzadas de los sistemas educativos nacionales y la noción de competencias}

Así como se han presentado grandes cambios económicos y políticos en el plano internacional en las últimas dos décadas -que algunos autores han bautizado con los eufemismos de Nuevo Orden Mundial o Globalización- también se han generado modificaciones en los sistemas educativos. Dichas transformaciones han estado directamente ligadas a los cambios mundiales, lo cual ha incidido en transformaciones curriculares en diversos países, como en Colombia. No sobra recordar que las políticas públicas de tipo nacional han ido quedando supeditadas a los requerimientos del capital transnacional, a través de la acción de organismos como el Banco Mundial, el Fondo Monetario Internacional y la Organización Mundial de Comercio. Esto supone la disminución en los gastos consagrados a la educación y la pérdida de autonomía en materia de planes de estudios e investigación.

Las acciones del capital transnacional, perfectamente articuladas con los intereses de las clases dominantes locales, se constituyen en el marco de referencia obligatorio para entender el impacto de las transformaciones mundiales en el sistema educativo colombiano, la crisis de la educación pública, el desmonte de las conquistas históricas de los do- centes y, por supuesto, los cambios en los planes de estudio escolares. En consecuencia, temas referidos a los nuevos lineamientos curriculares, las competencias ciudadanas, los estándares y las transformaciones de las facultades de educación, no pueden ser entendidos al margen de la modificación de las políticas públicas del Estado colombiano, ni deben ser vistos como resultado de una acción autónoma y original de las clases dominantes colombianas, que no se distinguen precisamente por su soberanía e independencia.

Para ejemplificar lo relacionado con las influencias externas sobre la política educativa en Colombia, vale considerar las competencias, término que ha ido extendiéndose a diversos ámbitos de la educación (incluso ya hay quienes, con poca originalidad, hablan de las "competencias ciudadanas"). Para empezar, el principal abanderado de las competencias es el Banco Mundial, como lo señala en uno de sus últimos informes sobre la educación: "Las competencias... combinan capacidades $\mathrm{y}$ valores interrelacionados (y) se pueden enseñar (aunque también es posible adquirirlas por fuera del sistema educativo formal)... El hecho de poseer competencias clave contribuye a una mayor calidad de vida en todas las áreas". Más adelante, el Banco Mundial precisa que las competencias deben conducir a la competitividad económica, puesto que "para desempeñarse en la economía mundial y en la sociedad global se necesita dominar habilidades de índole técnica, interpersonal y metodológica". Y describe cada una de esas habilidades:

Las habilidades técnicas comprenden las habilidades (sic) relacionadas con la alfabetización, idiomas extranjeros, matemáticas, ciencias, resolución de problemas y capacidad analítica. Entre las habilidades interpersonales se cuentan el trabajo en equipo, el liderazgo y las habilidades de comunicación. Las habilidades metodológicas abarcan la capacidad de uno aprender por su propia cuenta, de asumir una práctica de aprendizaje permanente y de poder enfrentarse a los riesgos $y$ al cambio (Banco Mundial, 2003).

Esas habilidades conducen a flexibilizar a los seres humanos, otro vocablo del arsenal de los neo- 
liberales. Si el mercado laboral se ha hecho flexible, por tal debe entenderse que los trabajadores ya no tendrán puesto fijo durante toda la vida, los sindicatos están prohibidos y predomina la lucha de todos contra todos. A la par, la educación también debe ser flexible y adaptable a los requerimientos del mercado de trabajo. Esta es la razón por la cual en los últimos tiempos ha emergido, en el mercado de saberes pedagógicos, la noción de flexibilidad. Esta se utiliza para responsabilizar al trabajador de su propia formación, para que sea competente y funcional al capitalismo. El planteamiento de la formación continua en cada país debe contribuir para que los "recursos humanos" sean flexibles, rentables, competitivos y sirvan a sus empresas. Trabajador que no lo haga ya no es empleable y ni siquiera es un "recurso humano", sino un desecho.

Estructurar la educación a partir de las competencias, tal y como las entienden el Banco Mundial, la Cepal y otros organismos burocráticos de ese estilo, significa que los sistemas educativos nacionales asumen de manera forzosa los supuestos de la competitividad en la era de la "sociedad de la información", abandonando la formación integral de los seres humanos, que debería ser el sentido profundo de la educación. En su lugar, la idea de "competencias educativas" es entendida como enfrentamiento entre individuos, empresas y países. Esas competencias deben favorecer la adaptabilidad de los "recursos humanos" al mercado competitivo mundial, exaltando el papel de las nuevas tecnologías, para que desde temprana edad los niños y jóvenes estén inmersos en un medio dominado por pantallas, teclados y ratones, respondan positivamente a las "órdenes" de un computador y se adapten a las modificaciones de programas informáticos. Como, al mismo tiempo, por el tipo de tecnologías empleadas se requiere cierta clase de saberes, se propone implementar un aprendizaje a lo largo de la vida útil del trabajador, siendo útil un sinónimo de productivo, lo cual significa que el trabajador debe sujetarse a los requerimientos de los empresarios capitalistas, y la educación simplemente debe ofrecer fuerza de trabajo barata y siempre dispuesta a someterse a las exigencias del sector privado.
Para el Banco Mundial la educación es una cuestión de costo-beneficio, planteando la reducción al extremo de la educación pública, la cual desde su estrecho punto de vista economicista no es rentable. Por ello, el pedagogo financiero en términos de costos recomienda varias cosas: reducción de los salarios de los profesores; disminución del número de docentes contratados; cierre de centros educativos, porque "los edificios escolares no son del todo necesarios para obtener los resultados académicos deseados", porque "hoy día el aprendizaje se logra todavía en muchos países sin que haya edificios, como ocurre en algunas zonas rurales de la India"; eliminación de la dieta alimenticia que en las escuelas se suministra a los niños, puesto que "muchos gobiernos mantienen grandes y costosos programas de alimentación escolar" (Banco Mundial, 1996).

El impacto del neoliberalismo en la educación se nota en la terminología empresarial empleada en estos momentos: ya no existen directores de escuelas, sino gerentes; los estudiantes y los padres de familia ya no son agentes activos del proceso educativo, sino clientes; los clientes deben incidir en el manejo de la empresa porque son los que la financian; los profesores son reducidos a simples proveedores de un servicio, negando su papel como sujetos de un proceso pedagógico; la educación debe ofrecer una amplia gama de ofertas para cautivar la demanda dinámica y diversa de sus potenciales clientes... Así, la educación es considerada como un negocio en el cual se produce un insumo (denominado capital humano) y su eficacia se mide en la relación costo-beneficio y en el efecto del capital humano sobre el empleo y el ingreso. Para superar la pobreza deben crearse condiciones para que los pobres tengan oportunidades de competir en el mercado de manera equitativa y para eso deben contar con su propio capital humano, que se ha formado en el sistema educativo, todo con la finalidad evidente de vender lo más barato posible su fuerza de trabajo (Rebellato, Extraido desde www.franciscanos.net/ teologos/mfal/rebelato.htm).

La educación se ha convertido en un artículo mercantil, como los automóviles o los teléfonos móviles, dominado por la lógica de la competencia, 
y sus resultados se han reducido a "indicadores de desempeño" estandarizados, que midan el grado de adiestramiento ("competencias") que han adquirido los usuarios (estudiantes) para ser competitivos en el mercado capitalista (Apple, 2001: 22). Esto explica la implementación de pruebas psicotécnicas, incluso en el ámbito universitario, como los Ecaes en Colombia.

Los saberes que poco aportan a las competencias básicas, tal y como las definen los empresarios capitalistas, son considerados como inútiles o incompetentes. Esos saberes inútiles son todos aquellos que contribuyen a una formación integral y crítica de cualquier ser humano, entre los cuales se encuentran la filosofía, la historia, la literatura, la geografía, la sociología y el arte. Esta anulación del saber crítico hace parte de la estrategia neoliberal, para el cual "no existe vocabulario para la transformación política y social, no existe visión colectiva, no existe direccionamiento social para desafiar la privatización y la comercialización de la escuela, la burda disminución de los trabajos, la liquidación en marcha de la seguridad laboral, o espacios desde los cuales luchar contra la eliminación de los beneficios para el pueblo (...)" (Giroux, 2002: 48).

Por estas pragmáticas razones, las competencias que pretenden introducirse en la escuela están relacionadas con la aceptación por parte de los trabajadores del "espíritu de empresa" para que acepten con resignación la flexibilización, para que no piensen en ser "in-competentes", como quien dice, para que renuncien a pensar, criticar, luchar y resistir la dominación del capital y cualquier tipo de opresión. Hay que formar competencias personales, aptitudes, que sean proclives a la flexibilización laboral y a la despolitización reinante en el mundo contemporáneo. $\mathrm{Al}$ respecto, la $\mathrm{OCDE}$ es rotunda cuando afirma que para difundir la defensa del "espíritu de empresa” se requiere una estrecha colaboración entre las empresas y la escuela, para que las primeras incidan en la aceptación plena de la "economía de mercado" y sus valores individualistas por parte de los estudiantes, con la finalidad de que estos aprendan a ser miembros "de un equipo de trabajo, a aceptar recibir órdenes y trabajar con los demás”, porque "se trata también de comprender mejor el ritmo de trabajo y estar dispuesto para responder a diferentes exigencias durante las etapas sucesivas de una carrera profesional" 1 .

Por esta circunstancia, en muchos países se ha propuesto la reducción de los conocimientos sociales y humanistas a favor de los saberes técnicos, reivindicando como razón de ser de la educación la lógica del lucro. Esto tiene consecuencias duraderas sobre la formación de la gente, si consideramos que las humanidades y las ciencias sociales no son un lujo superfluo, sino algo "útil" en su sentido más noble y elevado", porque "son necesarias para ayudarnos a formar nuestro juicio político sobre el presente, entendiendo lo político... como la actividad totalizadora y reflexiva, que a cada cual compromete, sobre el conjunto de los problemas que nos afectan a todos". La supresión de los conocimientos sociales en el ámbito educativo está creando un "círculo implacable de barbarie cognoscitiva y política"... y "dentro de este círculo resulta un lujo superfluo toda disciplina genuinamente humanista necesaria para la formación del juicio político del ciudadano, razón por la cual el círculo de la 'sociedad del conocimiento' deberá tender a cerrarse sobre la base de esta última exclusión de sus contenidos, la de los estudios de humanidades"?.

Con sus nociones de empleabilidad y productividad, el proyecto de las competencias no tiene ninguna ambición humanista: "No se trata de hacer aprender a todos y durante toda la vida los tesoros de la ciencia, de las técnicas, de la historia, de la economía, de la filosofía, de las artes, de la literatura, de las lenguas antiguas ni de las culturas extranjeras" 3 , porque todo esto en términos de las competencias indispensables para acoplarse a la supuesta "sociedad del conocimiento" es inútil, significa pérdida de tiempo, gasto de energía y despilfarro de recursos.

1 Citado por Nico Hirtt, Los tres ejes de la mercantilización escolar, en www.stes.es/nico.

2 Juan B. Fuentes Ortega y $\mathrm{M}^{\mathrm{a}}$ José Callejo Herranz, En torno a la idea de "sociedad del conocimiento": Crítica (filosófico-política) a la LOU, a su contexto y a sus críticos, en www.filosofia.net/materiales/ num/num17/Critilou.htm.

3 N. Hirtt, op. cit. 


\section{Repercusiones de las transformaciones educativas en las ciencias sociales escolares}

En el sistema educativo colombiano desde hace varias décadas viene desarrollándose una asignatura que responde al nombre genérico de Ciencias Sociales, por lo cual, hasta no hace mucho, solía entenderse a la historia y la geografía, como disciplinas separadas. Un primer paso, esencialmente burocrático, dado por las autoridades educativas del país tendiente a romper con esa concepción bitemática de ciencias sociales consistió en proponer la "integración" de los saberes, lo cual se hizo, tanto en los manuales como en la práctica diaria de los docentes, de una manera simple: en los textos escolares fueron agrupados bajo una misma carátula la historia y la geografía, pero analíticamente seguían bastante separadas una de la otra; en la práctica diaria, los docentes optaron, de acuerdo a sus propias fortalezas, por la historia o la geografía.

En los últimos años se ha ampliado la noción de ciencias sociales en la escuela, involucrando, además de la historia y la geografía, a otras disciplinas de manera más bien implícita, aunque esa ampliación vaya acompañada de una reducción de la intensidad horaria, y eso sin considerar los problemas estructurales de la educación pública, que hacen bien difícil materializar esa ampliación del objeto de las ciencias sociales escolares.

En medio de la confusión generada por la extensión del contenido de la noción de ciencias sociales escolares, ha quedado en evidencia que por decreto se pretende superar la concepción bitemática de historia y geografía, incluso como áreas integradoras. Incluso, en la legislación educativa (como en el Decreto Ley 272 de febrero de 1998, con el que se reforman las facultades de educación) se afirma de manera contradictoria que en la Educación Básica las áreas principales de las ciencias sociales son la historia y la geografía, aunque se exige que en la formación brindada por las universidades a los futuros profesores se rebasen los marcos de esas dos disciplinas y se incorporen los resultados de la moderna investigación en ciencias sociales, partiendo de la discutible afirmación que la "pedagogía se constituye en la disciplina fundante" de la profesión docente, dejando de lado los saberes específicos y los contenidos disciplinares.

En la concepción oficial del Ministerio de Educación Nacional desaparecen la historia y la geografía y todas las disciplinas específicas -en un país donde nunca se ha consolidado ninguna de ellas ni siquiera en el ámbito de la investigación especializada- para subsumirse en una nebulosa en la que hay de todo un poco, como aparece en los Lineamientos Curriculares, donde se hace referencia a 16 saberes sociales, al mismo tiempo que disminuye la intensidad horaria consagrada a los mismos (Ministerio de Educación Nacional, Lineamientos curriculares para el área de Ciencias Sociales). Esto simplemente es la supresión por exceso, si vale el término, de las ciencias sociales escolares, o su conversión en una especie de receta de cocina. Al final el estudiante no tiene ni siquiera información de lo más elemental en historia, geografía, economía o ecología. En la formulación de esos Lineamientos se plantea, para justificar la implementación de un híbrido inaprensible que allí se llama ciencias sociales, la superación de la historia de fechas y personajes. Esta actitud loable en principio termina justificando la desaparición de la historia y de la geografía, las cuales se subsumen en un número muy amplio de saberes sociales. Finalmente, se tira al niño con la bañera, es decir, a la historia y a la geografía como disciplinas escolares fundamentales en la formación de procesos de pensamiento, formas de razonar, niveles de identificación, y conocimiento de problemas concretos, esto es, espacial y temporalmente discernibles, con todo lo cual se limita la posibilidad de pensar históricamente. Como resultado de las tendencias señaladas, las áreas del conocimiento social se han convertido en unos discursos insustanciales, en gran medida rancia urbanidad o educación cívica.

En estas circunstancias, las ciencias sociales escolares en Colombia han ido convirtiéndose en saberes coyunturales, reactivos y ligeros. Coyunturales, porque se han convertido en el comodín de los caprichos de los mandatarios de turno, lo que implica que se recurre a ellas para legitimar los proyectos y las propuestas episódicas, y en gran medida 
sin sentido, de una determinada administración. Recuerdo en este momento el caso que conocí en la Universidad Industrial de Santander hace unos dos años cuando al gobernador del Departamento se le ocurrió la "genial" idea de "buscar la santandereneidad” y ordenó a los profesores, entre ellos a los profesores universitarios de historia, encontrarla rápidamente donde fuera y como fuera. Actitudes como esta, desde luego, impiden consolidar procesos de enseñanza y aprendizaje a mediano y largo plazos. De tal forma, no solo, se debe dar cuenta de lo establecido por la Ley (recordemos: historia, geografía, democracia, constitución, filosofía y ciencias económicas y políticas), sino que el profesor debe sacar tiempo para preparar a sus estudiantes en competencias ciudadanas, desarrollar el proceso anual de elección de gobierno escolar, cumplir con la cátedra afrocolombiana, desarrollar los proyectos transversales y los proyectos de aula, izar el pabellón nacional en las fiestas patrias, y llevar a cabo todas las actividades coyunturales y esporádicas que impongan las autoridades nacionales o municipales, donde se incluyen jornadas contra la violencia, campañas de vacunación y hasta pintorescos carnavalitos por la alegría y la diversidad.

Reactivos, porque en lugar de pensar en estructurar programas de formación articulados y encadenados, de tal manera que tanto estudiantes como profesores puedan hacer un seguimiento sistemático para evaluar procesos de aprendizaje, ahora lo que prima es la respuesta a situaciones coyunturales como las ya mencionadas. Como esas exigencias son circunstanciales, cuando pasan o cambia la orientación por la llegada de nuevos administradores a los gobiernos central o local, también cambia la ocurrencia sobre lo que debe pedirse a las ciencias sociales, sin importar la formación estructural de los estudiantes ni la cualificación de los profesores. Si de moda está, entonces, enseñar a cruzar por la cebra y cuando el semáforo está en rojo eso se convierte en tema de las ciencias sociales. Pero si luego la moda son las "competencias ciudadanas", los saberes sociales deben sujetarse a ese nuevo requerimiento, y así sucesivamente.
Ligeros (ligths), porque de ninguna manera apuntan a la formación del pensamiento crítico, autónomo e independiente de las nuevas generaciones alrededor del conocimiento de algunos de los problemas cruciales que aquejan a nuestro país y a América Latina. Por el contrario, contribuyen a generalizar la desinformación, la apatía, el conformismo y el individualismo extremo y a dejar la sensación de que en efecto el conocimiento social no tiene ninguna importancia ni utilidad, sino que es una especie de casuística más o menos arbitraria. Los conocimientos sociales ya no se ocupan de la historia y la geografía de Colombia y del continente, sino de cosas sin sentido, y eso en un país atravesado por incontables problemas. Para solo dar algunos ejemplos, en Colombia las ciencias sociales escolares deben ocuparse de "problemas tan trascendentales", como tomar el bus en el paradero indicado o sacar tarjetas amarillas a los infractores de tránsito. En esa misma dirección, las cátedras de democracia, en lugar de ocuparse de la antidemocracia que predomina en Colombia (uno de los países más desiguales e injustos del mundo) se dedican a dictar recetas de buen comportamiento, de pluralismo y de tolerancia en abstracto, como si eso fuera a resolver los problemas del país sin tener que modificar las raíces históricas de la desigualdad. Por su parte, la educación ambiental se limita a indicar a los estudiantes cómo recoger papeles en su colegio, sin considerar a los responsables de la destrucción ambiental del país y del mundo. Por todo ello, podemos concluir con Xavier Hernández que "mantener hoy con todo lo que está pasando en el mundo, que es importante saber leer el recibo de la luz o aprender a hacer la declaración de renta es sencillamente reaccionario"(Hernández, 1998).

Este tipo de estupideces son sofismas de distracción, si se tiene en cuenta el contexto social donde se producen, puesto que en lugar de aproximar a los estudiantes al conflictivo mundo en el que vivimos los conduce a cuestiones baladíes, que en nada contribuyen a proporcionar instrumentos de análisis y de crítica para actuar en concordancia con la magnitud de los problemas sociales de nuestro 
tiempo. ¿Para qué sirve saber atravesar la calle, si no se cuestionan la industria del automóvil ni su impunidad social y ambiental? ¿De qué vale hablar del respeto a los demás y del pluralismo retórico, si en todas las esferas del poder predomina la más absoluta desigualdad e injusticia? ¿Podemos solucionar el problema de la violencia en Colombia con recetas de concordia, cuando no se habla del reparto de la tierra, ni de la contrarreforma agraria que se ha llevado a cabo a sangre y fuego? ¿Puede detenerse la destrucción de nuestros ecosistemas solamente con llamados voluntaristas encaminados a convencernos de que todos somos responsables, sin mencionar a los agentes nacionales e internacionales que arrasan con la naturaleza? Como se aprecia, todos estos problemas no pueden entenderse en forma cabal sin tener en cuenta su dimensión temporal, sus orígenes, sus causas y sus manifestaciones espaciales, todo lo cual está relacionado con una perspectiva histórica y geográfica.

Para completar, ahora viene proclamándose que los contenidos ya no son importantes y que están subordinados a los métodos y a los procedimientos, como si estos pudieran desarrollarse al margen de contenidos disciplinares y de cualquier esfuerzo, prejuicio que hoy suele reivindicarse sin mucha vergüenza. En efecto, en forma genérica se supone que hoy no se requiere mucha consagración para aprender o investigar, como si pudieran asimilarse por generación espontánea los conocimientos que otros han producido mediante una labor tesonera y esforzada, con dedicación y disciplina. No, ahora se supone que los contenidos son secundarios y que puede saberse simplemente porque se dispone de unos procedimientos o de unos medios tecnológicos, sin tener que acudir a la reflexión teórica ni al conocimiento de temas y problemas. Así, por ejemplo, en los Lineamientos Curriculares se privilegia la formación de habilidades y se desprecia la transmisión de hechos y procesos, en una lógica en la que se replica algo que ya se ha dado en otros contextos, como en Estados Unidos, país en el cual en algunas instituciones se ha optado por enseñar los métodos de las ciencias antes que las ciencias en sí mismas. Es una forma curiosa de creer que puede aprenderse sin mayor esfuerzo y que "la gente educada no es aquella que ha leído muchos libros o aprendido muchos hechos, sino aquella que podría analizar hechos si alguna vez se encontrara con alguno, y que podría acercarse a los libros si fuese necesario hacerlo" (Caleb, 1990).

\section{Repensar la enseñanza de la historia y de la geografía en la época de la expansión mundial del capital}

A continuación señalamos la importancia que adquiere la enseñanza de la historia y de la geografía, cuando se anuncia que las naciones están en vías de desaparición. En primer término, examinamos muy de paso el tema de la nación y el nacionalismo, en contravía a las afirmaciones dominantes que postulan una nueva época, la globalización, en la cual ya no serían significativos los factores ligados a lo nacional. En segundo término, se menciona la trascendencia que podría adquirir la historia nacional. $\mathrm{Y}$, finalmente, esbozamos ciertos aspectos sobre la geografía nacional, en instantes en que el territorio adquiere una renovada valorización.

\section{Universalismo abstracto y nacionalismo cosmopolita en el mundo actual}

El discurso de la globalización considera que el Estado-nación ha sido superado y que todo lo que esté ligado a él no tiene ninguna perspectiva en un mundo que está irreversiblemente globalizado. Por esta razón, aquel discurso condena de antemano a las naciones, al nacionalismo, a la cultura nacional y a todos los aspectos relacionados con ellas. Como lo dice uno de los portavoces más citados de la ideología globalística, el brasileño Octavio Ianni, "si es verdad que la globalización del mundo está en marcha, y todo indica que así es, entonces comienza el réquiem por el Estado-nación" (Ianni, 1995).En el mismo sentido un autor español especializado en la enseñanza de la historia más recientemente ha dicho que "a partir de una crisis que se profundiza en los años ochenta con la caída del Muro de Berlín -que simboliza... también la del mundo decimonónico de las naciones- se trastruecan las identidades políticas y las soberanías nacionales en un mapa donde 
el modelo de articulación empieza a ser trans y no inter: el de la globalización planetaria" (Carretero, y Voss, 2004).

Si esto fuera cierto, no tendría sentido seguir enseñando lo nacional en sus múltiples dimensiones (histórica, social, geográfica, cultural, económica, lingüística, folclórica...), salvo como una especie de paleontología social, es decir, el estudio de entes fosilizados, pero que no tienen ninguna significación en el mundo actual. Es apenas normal que si ya no tienen sentido las naciones y las culturas a ellas ligadas, tampoco lo tendría la enseñanza de algo relacionado con lo nacional. Esta suposición sería válida si esa nebulosa globalización existiera en el mundo de hoy, y ya las naciones hubieran desaparecido. Pero tal anunció no solo es optimista, sino profundamente irreal, porque las naciones siguen existiendo y seguirán estando en la vida de las sociedades por mucho tiempo.

Entre otras cosas, los portavoces más radicales de la dominación imperialista y los representantes de las multinacionales o de organismos financieros difunden un universalismo abstracto, según el cual habrían desaparecido las fronteras, los pasaportes, los obstáculos a la libre movilización por la faz de la tierra y todos los seres humanos nos beneficiaríamos de los frutos positivos de una globalización feliz. Este discurso se difunde para consumo de los incautos, porque en realidad las multinacionales y sus voceros sí que tienen una nacionalidad definida y un Estado-nación que los defiende, como todos los días lo demuestra Estados Unidos con su oposición a que sus ciudadanos, incluyendo a los militares, mercenarios y criminales, sean juzgados por otro país o por cualquier instancia supranacional.

El universalismo abstracto justifica el despojo de los países, sosteniendo que las naciones ya no tienen importancia porque la globalización ha traspasado las fronteras y el nacionalismo nos remite a un obsoleto "sentimiento tribal", hoy superado por los vientos globalizadores que soplan en todas las direcciones. Los hechos cotidianos demuestran que el universalismo abstracto solo es un discurso apologético de la renovada dominación imperialista que pretende también impedir la concreción de luchas sociales y políticas de tipo nacional. Entre esos hechos cotidianos podemos mencionar la represión a los inmigrantes, el cierre de fronteras, la construcción de muros de la infamia en Israel y Estados Unidos, el incremento de los prisioneros extranjeros en las cárceles de los países imperialistas, los bombardeos indiscriminados a aquellos países opuestos al nuevo desorden mundial, la condena y el arrinconamiento a cualquier proyecto nacionalista que favorezca algún interés popular, como se demuestra en estos momentos con Bolivia.

En contra de ese universalismo abstracto hay que promulgar un pensamiento nacional cosmopolita, que conjugue lo internacional con lo nacional y lo general con lo concreto, que respalde las luchas nacionales que defienden las riquezas materiales, la cultura y los valores democráticos de diversos pueblos de la tierra. Pero al mismo tiempo, desde la perspectiva de un internacionalismo concreto, debe criticarse radicalmente el nacionalismo estrecho y chovinista de tintes neofascistas que pretende imponer una supuesta pureza étnica y racial para diferenciar a los "nacionales" del resto de seres humanos. Es necesario distinguir los diversos tipos de nacionalismo que existen, puesto que allí se encuentran desde proyectos chovinistas y xenófobos (como sucede ahora mismo en Estados Unidos, España o Francia) hasta proyectos antiimperialistas (como en Palestina, México o Bolivia).

Una cosa es criticar al nacionalismo chovinista y racista y otra aceptar el universalismo abstracto, como el que hoy venden autores, como Mario Vargas Llosa, que exaltan los supuestos beneficios de la globalización, a nombre de lo cual condenan toda lucha nacionalista por considerarla intrínsecamente reaccionaria y conservadora, desconociendo que las reivindicaciones de distintos sectores en el mundo combinan la lucha nacional y social por preservarse como nación y destruir la opresión y explotación de clase. Esto demuestra, en pocas palabras, que "el nacionalismo es como un martillo, que puede ser una herramienta o un arma, según cómo lo usemos" (Fontana: 102, 31).

La reivindicación de un nacionalismo incluyente apunta, entre otras cosas, a señalar que no es posible 
defender en el vacío la condición de "ciudadanos del mundo", un término de la retórica posmoderna y neoliberal muy manoseado en estos tiempos. Al respecto vale indagar si "ciudadanos del mundo" son los indonesios pobres que trabajan en barcos fábricas en aguas internacionales a cambio de medio dólar diario y que no tienen ningún derecho laboral, ni político, o lo son los miles de inmigrantes que tratan de llegar a Europa atravesando el océano y que son tratados peor que animales, o lo son los millones de latinoamericanos que diariamente son perseguidos, encarcelados o asesinados por la "migra” estadounidense en la frontera norte de México. Evidentemente, ninguno de los mencionados puede considerarse, según la definición artificial y de moda, como parte de los "ciudadanos del mundo", ya que ese pomposo nombre está reservado a los miembros de la burguesía transnacional, estrellas del deporte o la farándula y uno que otro intelectual globalizado dispuesto a venderse al mejor postor.

La aclamada "ciudadanía mundial" solo puede ser disfrutada por una ínfima minoría de los 6.000 millones de habitantes del planeta tierra. En gran parte del mundo, los humildes hombres y mujeres ni siquiera gozan de la "ciudadanía barrial", ya que no tienen trabajo estable, están desempleados, sobreviven del rebusque diario, soportan la persecución y la brutalidad policial, no tienen acceso a la educación ni a la salud, y en todos los lados se les acusa y estigmatiza por el solo hecho de ser pobres. El mito de la "ciudadanía mundial" revela claramente la polarización que genera este apartheid posmoderno: tecnócratas globales y burguesía transnacional de un lado y pobres, desarraigados y "clases peligrosas" y estigmatizadas de otro.

Los mismos que hablan de ciudadanía mundial son los que plantean la constitución de una "sociedad civil global". La cuestión fundamental es determinar quiénes serían los miembros de esa hipotética sociedad global: “ ¿Los africanos, los sudamericanos? ¿El carpintero y la modista de mi barrio?” (Mires, 2000: 47). Para los globalistas esto parece ser un problema secundario, pues lo verdaderamente importante estriba en las múltiples posibilidades comunicativas que ha generado la revolución microelectrónica para estar en contacto entre personas de distintos países y para desplazarse de manera instantánea por el espacio virtual. Aunque los contactos a través de Internet aumentan las posibilidades de comunicación, eso no sustituye las vinculaciones locales a un espacio y a un territorio dado, es decir, a una sociedad concreta, ni la comunicación interpersonal, que es la única en que podemos ser personas, y no simples números, códigos o imágenes como lo seríamos en el espacio virtual. De aquí se desprende que "ciudadanizar al mundo en una sociedad global significaría nada menos que deslocalizar los espacios de realización social. Los pocos que nos quedan", lo cual quiere decir que "el lugar de realización de la civilidad no puede ser imaginario o abstracto; tiene que ser la nación como espacio constitutivo de lo social". Por todo ello, quien se decida a escribir sobre ciencias sociales y no sobre ciencia ficción "no puede estar de acuerdo con la idea de sociedad civil global. Significaría, en buenas cuentas, estirar tanto los términos de sociedad y civilidad, que al final no servirían para nada" (Mires, 2000: 46-48).

\section{Una reivindicación de la enseñanza de la historia nacional en tiempos de mundialización del capital}

En la vida real para la gran mayoría de los habitantes del mundo, la base fundamental de identificación sigue siendo su territorio y todo lo que está asociado al mismo, aunque por supuesto existen grupos minoritarios de la población que hacen parte de una cosmocracia en ciernes, una burguesia transnacional, que se identifican más con Europa o Estados Unidos (Duclos, 2002:31 y ss.). Esto tampoco tiene nada de nuevo, pues desde la Independencia esa ha sido una característica de las clases dominantes de los países de América Latina, siempre prestas a identificarse con los poderes imperiales, renegando de sus vínculos con los pueblos que habitan en los territorios periféricos. Para justificar esa negación inventaron algunas convenciones contra la cultura, para ocultar la existencia de negros, indios, campesinos y artesanos que los rodeaba, a todos los cuales consideraban inferiores e incapaces, siendo señalados como el principal obstáculo para alcanzar la "civilización" y el "progreso". 
Por supuesto, es inútil desconocer el impacto de lo que puede llamarse una desterritorialización simbólica, que se propaga por los medios de comunicación de masas, principalmente a través de la televisión. Para las vastas mayorías esa desterritorialización solamente es imaginaria, porque los sueños globales del American Way of Life no pueden ser satisfechos y se convierten en pesadillas locales que contribuyen a erosionar el tejido social de la vida cotidiana y a romper los nexos comunitarios $\mathrm{o}$ asociativos antes existentes entre los pobladores urbanos o rurales en cada país. Solo una reducida minoría se beneficia de la desterritorialización cultural al disfrutar de los bienes de consumo producidos por las multinacionales o viajar a Estados Unidos y Europa. Considerando esta compleja situación, la geografía escolar debería contribuir a reconstruir nexos territoriales y a esbozar propuestas que permitan afianzar los vínculos de los estudiantes con sus localidades, en las cuales transcurre una parte sustancial de sus vidas.

La enseñanza de lo nacional sigue siendo necesaria porque en estos momentos lo local y lo mundial están íntimamente vinculados y porque los grandes problemas del planeta adquieren presencia en las naciones, en su historia concreta, y solo pueden ser solucionados a partir de la comprensión específica de esa sociedad y de sus tradiciones. Pero desde luego esa visión nacional debe estar enriquecida por las influencias mundiales, para entender las cuestiones acuciantes del presente histórico de cada país. Esas ciencias sociales de tipo nacional no deben reducirse a lo puramente interno, algo poco deseable y prácticamente imposible en los días que corren. Por eso su enseñanza debe conjugar lo nuestro con el conocimiento de los otros, los que son diferentes, para impedir que a nombre de lo que se presenta como novedoso, y que viene de afuera, se destruyan las culturas nacionales.

En forma dominante la enseñanza de la historia nacional y su pretensión de forjar cierta identidad durante los siglos XIX y XX en los países de América Latina estuvo signada por el proyecto excluyente de las clases dominantes de construir unas naciones mutiladas, en las cuales no se reconocía la existencia de aquellos proclamados como inferiores y que no debían mancillar la nación "blanca" y "letrada", construida pretendidamente a imagen y semejanza del mundo civilizado, esto es, europeo o estadounidense (Múnera, 2005; Larson, 2002). Es evidente que este tipo de discurso histórico, que configura la denominada "historia patria", nunca fue representativo de la composición social, variada y multiétnica, de los pueblos latinoamericanos, sino de los minoritarios sectores dominantes. Pero, desde luego, otros grupos sociales han pugnado por una nación incluyente, en la que cupieran todos, y en muchos casos con sus acciones prácticas de resistencia han propuesto otra forma de construir nación, como se ha hecho evidente y actual con las rebeliones indígenas que han sacudido a varios países de América Latina en los últimos años (México, Bolivia y Ecuador).

En este contexto, cabría señalar que esa otra forma de concebir la nación y de reivindicar la historia de los otros, de los excluidos y marginados de siempre, ha sido clave en el proceso de definir la personalidad de un pueblo para conferir identidad y sentido a un determinado proyecto histórico. ¿Qué sucede con esas historias nacionales en momentos en que se presentan cambios mundiales significativos? ¿Tenemos que resignarnos a observar su muerte ante la avalancha homogenizadora de los tiempos actuales? ¿Toda historia nacional deja de ser significativa ante la mundialización capitalista?

Podríamos tomar algunos ejemplos de actualidad como marco de referencia para considerar el caso de la historia nacional y de su enseñanza. Hablemos, de una parte, del retorno de la historia xenófoba y chovinista y, de otra parte, de un sentido diferente, democrático e incluyente, que podrían asumir las historias nacionales en medio de la mundialización del capital.

Como en diversos lugares del mundo ha resurgido la xenofobia y el racismo, allí la historia escolar discurre por los canales nacionalistas más extremos e intolerantes. Tal es el caso de Israel, donde desde la escuela y los medios de comunicación se legitima el asesinato de los palestinos, la destrucción de sus viviendas, la expulsión de sus tierras y la construcción de un aterrador muro de la vergüenza que pre- 
tende separarlos permanentemente de los israelitas. Además, en importantes sectores del estado sionista de Israel se plantea una especie de "solución final" de la cuestión Palestina mediante la expulsión de todos los no judíos o la redefinición unilateral de las fronteras por parte del Estado de Israel, lo que no deja de ser una propuesta delirante e imposible de llevar a la práctica con éxito, pero que sí origina crímenes diversos contra millones de seres humanos que malviven arrinconados en lo que les queda de sus territorios históricos, como podemos observarlo todos los días.

Parece paradójico que la historia chovinista cobre fuerza en el mismo instante en que se nos anuncia la unificación del mundo, el fin de las fronteras, la aparición de una sociedad civil planetaria, la emergencia de una ciudadanía mundial y tantas bellezas por el estilo. El caso de Israel evidencia un comportamiento chovinista y racista sustentado en cierto tipo de discurso histórico, al que Marc Ferro llamó en una ocasión "el segundo catecismo" (Ferro, 1970: 33), que se impulsa desde las escuelas y se sustenta en mitos nacionales racistas y discriminatorios, basados en la mentira y la falsificación de los procesos históricos (Hosbawm, 1998: 17 y ss.). Desde allí se exaltan las virtudes nacionales, la pureza de raza, la grandeza de espíritu, el supuesto control ancestral de un territorio, todo magnificando los valores de la "raza nacional" y construyendo una imagen negativa de los que son presentados como "enemigos", a los que se les anuncia su pronto exterminio. Este es un tipo de discurso retrógrado que rechaza la integración de pueblos y culturas diferentes, a partir de la lógica de la exclusión y del exterminio, enarbolando la bandera del miedo a que la nación se contagie por la irrupción de los "bárbaros". No es casual que, para justificar el genocidio contra el pueblo palestino, el poderoso grupo judío de Estados Unidos haya convertido el "holocausto" en una poderosa industria y haya contribuido a reforzar los mitos fundadores del Estado de Israel, acusando como antisemitas a todos aquellos que se atrevan a criticarlo (Finkelstein, 2002).

Al mismo tiempo, como en las potencias imperialistas se agudizan los problemas generados por la mundialización del capital (desempleo, exclusión social, desmonte de los mecanismos redistributivos de los Estados, privatizaciones, pobreza...) también cobran fuerza los discursos xenófobos y racistas, impulsados por sectores de las clases dominantes que no quieren incómodos extranjeros en sus "paraísos”. Ese discurso intolerante ha vuelto a cobrar fuerza en diversos lugares del mundo, incluyendo a Estados Unidos y Francia, países no solo de tradición liberal en términos políticos, sino que en términos culturales se han nutrido con el aporte de las más diversas matrices geográficas, étnicas y lingüísticas. Si el Frente Nacional de extrema derecha dice que Francia está en peligro por la afluencia de extranjeros indeseables, que mancillan los valores puros de los galos, no solo está haciendo uso de la demagogia política, sino que está actualizando un tipo de discurso escolar, que los franceses desarrollaron en las décadas de 1950 y 1960. En este discurso se ensalzaba a la nación francesa como el centro del mundo, pero excluyendo al mundo, y con criterios similares ahora se pretende responsabilizar a los "extranjeros" por los males que aquejan al país (Jaulin, 1980: 91 y ss.).

En Estados Unidos, Samuel Huntigton, uno de las vedettes intelectuales de la derecha, ha renovado su teoría del "choque de civilizaciones" señalando que la intromisión indebida de los latinoamericanos en la vida de Estados Unidos está erosionando los valores civilizados de ese país y pone en peligro su misma existencia. "En esta nueva era de la globalización”, dice Huntington, “el único desafío inmediato y más serio a la identidad tradicional estadounidense procede de la inmensa y continúa inmigración de Latinoamérica, especialmente de México", porque los latinos se reproducen como conejos, siguen hablando castellano y no se integran con el resto de la sociedad estadounidense4.

Por otra parte, algunos historiadores europeos rechazan, a partir de las experiencias xenófobas y ra-

4 En su último libro, Who we are? (Quiénes somos?), Samuel Huntigton hace este tipo de apreciaciones. El texto citado aparece en Gobernador acusa Huntigton dar argumentos derecha racista, en yahoo noticias, marzo 27 de 2004, htp://mx.news.yahoo. com/040327/38/16fmd.html. 
cistas, todo tipo de historia que refuerce el nacionalismo y la identidad, por considerar que las naciones han sido superadas por fenómenos transnacionales, en los planos económico y cultural (Hosbawm, 1991: 230-245, 250-263). Esta consideración parece muy rotunda y genérica, puesto que incluye allí todo tipo de sentimiento nacional, tanto el que conduce a la limpieza étnica como el que lleva a proyectos de liberación nacional en distintos lugares del mundo, que tienen una indudable legitimidad histórica. En ese sentido, no pueden equipararse las reivindicaciones nacionales que en diversos lugares del planeta efectúan movimientos sociales y políticos, con la xenofobia o los fundamentalismos, so pena de negar la importancia de las naciones en el mundo contemporáneo, las luchas de liberación nacional y los procesos de descolonización que tan importantes han sido en la historia de la segunda mitad del siglo $\mathrm{XX}$. Por esas posibilidades diversas, el nacionalismo no puede ser descalificado a priori como una de las aberraciones de comienzo de milenio, porque "en realidad lo que suele condenarse son los nacionalismos de los demás, y en especial los reivindicativos, que resultan muy molestos para los que hablan desde el cobijo de un Estado nacional consolidado, donde ni siquiera hace falta ser nacionalista y puede incluso presumirse de estar por encima de estas cosas" (Fontana, 2003: 175).

La lucha de los zapatistas en México, para señalar un caso concreto, se hace a partir de la reivindicación de un proyecto nacional democrático y popular, pues ese país ha sido feriado por los neoliberales mexicanos a Estados Unidos. Por eso, en una de sus máximas los zapatistas afirman que el "neoliberalismo es enemigo de la historia, de la tierra y de la cultura" (Vega, 1997: 389-392). Entre otras cosas, en el abandono del nacionalismo como proyecto del Estado mexicano actual, rubricado durante el gobierno de Salinas de Gortari con la firma del Tratado de Libre Comercio de América del Norte (TLCAN) con lo que se renunció a la herencia de la Revolución de 1910, la administración de Estados Unidos jugó un papel activo. En efecto, el gobierno de Bill Clinton presionó para que fueran modificados los textos escolares de historia, con la perspectiva de que en nuevos manuales se les proporcionara a los niños mexicanos otra imagen de Estados Unidos y de sus relaciones con México ${ }^{5}$. En los nuevos tiempos de TLCAN se necesita una historia escolar que refuerce la idea de que Estados Unidos ha contribuido al desarrollo de México, que ha hecho inversiones productivas que han favorecido a todos sus vecinos de la frontera sur, que ha sido un socio amistoso e incondicional del pueblo mexicano y mil mentiras más. Esto supone, nada más y nada menos, que una revisión de la historia nacional de ese país y el abandono del nacionalismo, con el objetivo de adecuar a las nuevas generaciones de mexicanos al neoliberalismo y al libre comercio.

Siguiendo con esta lógica, el gobierno neoliberal de Vicente Fox intentó imponer en el 2004 y otra vez en el 2006 una reforma en la enseñanza de la historia escolar, encaminada a reducir el tiempo dedicado al conocimiento de las sociedades indígenas precolombinas y, en general, a la historia mexicana. Este proyecto ha generado una fuerte oposición entre historiadores, artistas e intelectuales de ese país, uno de los cuales ha señalado que las modificaciones de los planes de estudio están inscritas en la lógica del "Plan Puebla-Panamá, con el que nos quieren hacer iguales". Eso conduciría a la homogenización de "las costumbres, la historia de nuestros pueblos, la memoria colectiva", y al "fin de las comunidades, la desintegración de la familia para formar maquiladoras en esta zona que abarca Puebla, Panamá hasta el Caribe, y que son alrededor de 65 millones de personas, casi la mayoría de origen indígena. De tal manera que esto es gravísimo, es la acción más perversa y más criminal contra nuestra colectividad nacional" (Bañuelos, 2004).

En el proceso de expansión mundial del capitalismo la ideología cumple un papel fundamental, siendo uno de sus principales objetivos machacar algunas ideas con fuerza: estamos en el fin de la historia, el capitalismo es insuperable y no hay ninguna alternativa en el horizonte. Para ello, cierto

5 Véase Mario Carretero, La mirada del otro y la enseñanza de la historia, en www. didacticahistoria.com/ccss/ccss28.htm. También M. Carretero y J. F. Voss, op. cit., pp. 92-93. 
tipo de discurso histórico ha sido apuntalado por el imperialismo, a nombre de una globalización irreversible, con la finalidad expresa de fabricar pueblos bonsái, ya que "al privarlos de su conciencia histórica cercenan sus raíces y los vuelven pueblos enanos, eufemísticamente llamados 'subdesarrollados' por sus dominadores, que de esta manera pueden -así lo suponen ellos- ser controlados con toda facilidad" (Sánchez Quintanar, 1998: 296). Esto explica, entre otras cosas, uno de los orígenes recónditos y poco conocidos del proyecto de dejar de enseñar historia, y sobre todo historia nacional.

Con este ejemplo hemos querido mostrar que existe un interés explícito por parte de las grandes potencias de borrar ciertos aspectos de las historias nacionales, considerados incómodos en su proyecto de reafirmación de su hegemonía mundial. Dicho interés no es resultado de las fuerzas espontáneas e irreversibles del mercado y de las tendencias ineluctables de la globalización como se nos repite hasta el cansancio. Se constituye, por el contrario, en un intento consciente de borrar la memoria colectiva de un pueblo con la finalidad de asegurar sus propósitos actuales de dominación. Es como si un país no tuviera historia y esta empezará solo ahora con la mundialización del capital y como si tampoco fuera portador de una cultura viva, que se ha moldeado históricamente, porque "en los tiempos modernos la reflexión sobre el intercambio cultural supone reflexionar también acerca de la dominación y la apropiación por la fuerza: alguien pierde, alguien gana" (Said, 1996: 305).

Desde un punto de vista opuesto tanto a la historia chovinista como a los planteamientos del universalismo abstracto, sigue teniendo sentido la enseñanza de la historia, incluyendo a la historia nacional, siempre y cuando esta no sea heroica, patriotera o legitimadora del odio racial y de la discriminación. Es necesario volver a examinar la historia nacional de cada país, en concordancia con las transformaciones del mundo, para poder entendernos mejor y comprender el carácter de nuestra inserción en el capitalismo actual, para no ver los procesos como resultado de la fatalidad histórica, sino como producto de una evolución compleja y contradictoria. Porque un país en el que se sacrifica una parte de su cultura -como sucede hoy en Colombia- se empobrece y es presa fácil de las "nuevas" formas de dominación imperialista, como se pone de presente con la imposición de un Tratado de Libre Comercio, tan desconocido como antidemocrático, o con una Ley Forestal que ha sido hecha para facilitar que las multinacionales de la madera se lleven nuestros bosques, selvas y páramos.

En estos tiempos es indispensable conocer la historia nacional, no solo porque las culturas nacionales y locales persisten, sino porque en realidad no existen seres humanos desterritorializados ni "ciudadanos del mundo", como algunos lo anuncian triunfalmente. Los seres humanos se funden con el territorio y el lugar donde nacen y donde se educan, de allí aprenden tradiciones, valores, construyen elementos de identidad y se nutren de la memoria de un pueblo o de una región. Luego, si abandonan ese territorio, sus valores culturales adquiridos son los que les permiten relacionarse con otras culturas y desenvolverse en otros lugares. Su acción en este nuevo territorio cultural se hace a la luz de su historia, tradiciones y costumbres, porque los seres humanos no pueden actuar como si fueran cáscaras vacías, desprovistos de memoria.

El diálogo con lo universal, para que sea eso, diálogo, y no calco y copia, debe apoyarse en las fibras nacionales, en el conocimiento de la personalidad histórica de un pueblo, esto es, de su memoria, su cultura, su lengua, sus hábitos alimentarios, sus mejores tradiciones, pero no para regodearse como si se fuera el ombligo del mundo, sino como parte del autorreconocimiento de sus límites y posibilidades. Esta es una condición indispensable para establecer una mejor relación con el mundo, para ver y compartir diferencias, para aprender de otras culturas, pero sustentado en una base firme que solo se construye a partir del conocimiento de lo propio. Este conocimiento es, entre otras cosas, uno de los soportes de la ciudadanía real y no retórica, ya que

\footnotetext{
la función primordial de la historia está centrada en ubicar e identificarnos en la sociedad que nos tocó vivir, en nuestro aquí y ahora a partir del conocimiento de nuestro pasado y en darnos
} 
los elementos necesarios para pensar nuestro futuro.

Cuando de la identidad se trata, la Historia aporta elementos valiosos para alcanzarla. La Historia en la escuela es una disciplina que tiene mucho que ver con la formación ciudadana. El proceso de identidad generalmente se lleva a cabo a través de la memoria colectiva y de la conciencia histórica (Lamoneda, 1998: 276).

Si estamos hablando de una historia, como la de nuestra América, que reivindique las mejores tradiciones indias, negras y mestizas y los procesos de resistencia, que denuncie las formas de explotación y saqueo que durante cinco siglos han realizado las potencias mundiales y sus súbditos locales, que ponga de presente la vitalidad de unas culturas enraizadas en la memoria histórica de las comunidades, que muestre cómo sucesivos procesos de integración al mercado mundial han tenido consecuencias contradictorias sobre las sociedades nacionales, este será un programa de historia nacional también renovador, en la medida en que no sea ni eurocéntrico ni chovinista. Esto mostrará, a su vez, que una plena integración al mercado mundial es imposible y, además, sí fuera viable, sería catastrófica para un país no preparado para dar ese paso, como está demostrándose con la mayor parte de los países del continente. Esa historia nacional también señalaría la urgencia de resolver problemas pendientes, que permitan una mejor integración en lo universal, a partir del reconocimiento de lo propio. La enseñanza debe conjugar lo nuestro con el conocimiento de los otros, los que son diferentes, para impedir que a nombre de lo que es novedoso y que viene del mundo se aplaste y se destruyan las culturas nacionales.

La historia nacional y su enseñanza siguen siendo necesarias porque lo local y lo mundial están íntimamente vinculados y porque los grandes problemas del planeta adquieren presencia en las naciones, en su historia concreta y solo pueden ser solucionados a partir de la comprensión específica de esa sociedad, de sus tradiciones y su historia. Es imposible seguir hablando del estudio de lo nacional, o de lo regional y local, sin establecer vínculos con el resto del continente latinoamericano y el mundo. Esto significa que la dimensión nacional de los fenómenos sociales no es la única variable, si es que alguna vez lo ha sido, que nos permita comprender los grandes problemas que afronta un país, y más aún cuando en los actuales momentos en América Latina retoma fuerza la dominación imperialista de Estados Unidos y de sus grandes empresas multinacionales. Pero eso sí, deben encadenarse adecuadamente las cuestiones nacionales con las nuevas formas de dependencia (que ya no se use el término no quiere decir que la dependencia haya desaparecido) para explicar los problemas generados por la expansión mundial del capital.

No estamos diciendo que solamente vaya a enseñarse historia nacional o ciencias sociales de tipo nacional, lo cual no tendría ningún sentido en medio de los avances en el conocimiento universal y considerando la magnitud de problemas que afrontan los seres humanos en todo el mundo, sino que esos saberes deben convertirse en los ejes fundantes de las ciencias sociales escolares, en torno a los cuales deberían articularse otros aspectos y temas del conocimiento escolar, que permitan relacionar a Colombia con América Latina y con el mundo. Esto es posible porque el conocimiento histórico se constituye en una base de sustentación de nuestro tiempo y de la acción de los seres humanos hoy, porque "la historia es, por excelencia, el conocimiento fundante del presente" (Sánchez Quintanar, 1998: 295).

La historia nacional, según Enrique Florescano, debe "dotar a un pueblo de un pasado común y fundar en ese origen remoto una identidad colectiva", la cual es "quizá la más antigua y la más constante función social de la historia”. Así mismo, hay que tener en cuenta que la historia requiere "una curiosidad hacia el conocimiento del otro, una disposición para el asombro, una apertura a lo diferente y una práctica de la tolerancia", porque "la historia es el oficio de la comprensión", lo cual posibilita acercarse a aquello que es distinto de lo nacional, ya que

(...) la historia al recoger y ordenar el conocimiento del pasado, se convierte en el almacén 
de la memoria colectiva, en la salvaguarda de la nación. La historia es el saber que da cuenta de las raíces profundas que sostienen las sociedades, las naciones y las culturas y, asimismo, es la disciplina que esclarece el pasado de los individuos: es el saber que desvela las raíces sociales del ser humano (...).

Desde el inicio de la vida civilizada el conocimiento histórico ha sido el mejor instrumento para difundir los valores de la cultura nacional y para comprender el sentido de la civilización. En ese sentido la enseñanza de la historia es uno de los conductos más adecuados para conocer los valores universales que han guiado a la humanidad y un transmisor eficaz de los valores e identidades nacionales 6 .

Esta es una muy buena síntesis de la importancia que tendría una historia nacional incluyente en la época que nos ha tocado vivir. A eso solo habría que agregarle la sugerencia de Josep Fontana, para quien a un joven de nuestro tiempo debe enseñársele que

el panorama del mundo social en que vive es tan contingente como el del paisaje físico de su entorno y que, como aquel, puede ser modificado. Que no hay nada "natural","sagrado" e intocable en ese paisaje social, más allá de un único principio ético fundamental que es el del reconocimiento del derecho de todo hombre y toda mujer a su vida, libertad y dignidad. Todo lo demás es discutible y todo puede ser cambiado, y debería ser cambiado cuando convenga a los más (Fontana, 2003: 122-123).

Esto implica que no pueden pensarse ni enseñarse ideas referidas a supuestas identidades inmodificables al margen de las grandes transformaciones del mundo, porque en la realidad las naciones y sus culturas cambian en forma permanente, justamente porque son productos históricos, con toda la complejidad contradictoria que eso supone, y no reliquias de museo, fijas y estáticas.

6 Enrique Florescano, Para qué estudiar y enseñar la historia, en www.geocities.com/revista_conciencia/florescano.html.

\section{La renovada actualidad de la enseñanza de la geografía nacional}

Continuamente se asegura que la globalización supone el fin de las fronteras nacionales $y$, por consiguiente, el fin de la geografía tal y como hasta ahora se había considerado, es decir, circunscrita a los límites territoriales de tipo político fijados por los Estados nacionales. Ahora se nos dice que esto ha sido puesto en cuestión por las fuerzas irreversibles de la globalización, por los movimientos incontrolados del capital financiero transnacional, por la información que circula a través de Internet y la televisión satelital y por la comercialización internacional de bienes y mercancías. Para empezar, en sentido estricto nada de eso es nuevo, si se tiene en cuenta que a lo largo de su historia el capital ha tendido a comprimir el espacio y acelerar el tiempo. Lo primero supone el empequeñecimiento del mundo, motivado en gran medida por los desarrollos en los sistemas de comunicación y de transporte, en los que sucesivamente se han presentado avances desde hace cinco siglos (Harvey, 1995: 240 y ss.). En tal perspectiva, Internet es un momento más en esas innovaciones tecnológicas, como ayer lo fueron el telégrafo, el teléfono y la televisión. Lo segundo implica la constitución de un ritmo vertiginoso, regido por la lógica de la acumulación y la ganancia, que abarca todos los procesos, desde la producción hasta el consumo y que también influye en la remodelación espacial. En otras palabras, el reajuste del espacio es una tendencia permanente del capital, como se expresa en procesos contemporáneos como el traslado de plantas de producción de un continente a otro, la desindustrialización en varios lugares del mundo, la apertura de zonas francas y de maquilas, la consolidación de nuevas ciudades como centros de actividad económica y financiera... 7 .

Precisamente, en estos momentos la geografía nacional adquiere un nuevo sentido si se inscribe en la lógica de la explotación global del capitalismo. Así, el territorio y los recursos de un país adquieren una

7 D. Harvey, El 'nuevo' imperialismo: sobre reajustes espacio-temporales y acumulación mediante desposesión (I), en www.viento delsur.info/articulos.web/textos/index.php?x=195/196. 
importancia renovada en la expansión del imperialismo, que hoy como ayer busca controlar recursos naturales y energéticos, materias primas, minerales $y$, ahora, fuentes de agua y biodiversidad, pero también incorporar nuevos territorios como zonas de producción, con bajos salarios y pésimas condiciones laborales, o abrir nuevos mercados para los productos de las multinacionales. Todos estos procesos han sido denominados por el geógrafo marxista David Harvey como el proceso de acumulación capitalista por la vía de la desposesión permanente de grandes reductos de la población (Harvey, 2004: 111 y ss.). En estas condiciones, otra vez se asiste a la reprimarización de las economías del mundo periférico, lo que trae aparejado un reordenamiento espacial, en lo relacionado con la disposición de infraestructura para la exportación, la destrucción acelerada de recursos y biodiversidad, la implantación de unidades productivas controladas por las multinacionales (maquilas y fábricas de la muerte), dominación y recolonización de los países en concordancia con los intereses estratégicos del capitalismo mundial y el abandono económico de territorios que ya no son significativos para el imperialismo, aunque sigan dominados política y militarmente, como sucede en gran parte de África.

Eso que de manera muy benigna se llama "globalización" supone, por consiguiente, la reedición de algo ya visto en la historia latinoamericana de los últimos cinco siglos, como es el acelerado despojo de productos primarios y de recursos naturales, junto con una explotación acentuada de trabajadores, campesinos e indígenas. A la par que en la vida real se desarrolla ese saqueo, los ideólogos de la globalización nos dicen que ahora los recursos materiales no son importantes, puesto que en la "sociedad del conocimiento" pasarían a estar subordinados a los flujos de información y a la sociedad red. Es decir, que el territorio de un país, sus recursos y sus habitantes, elementos absolutamente indisociables, están siendo sometidos a un proceso intensivo y acelerado de explotación, como se observa en la mayor parte del continente latinoamericano, por parte del imperialismo, lo cual se convierte en una condición para que sus ideólogos difundan la idea de que la geografía nacional ya no interesa. Por supuesto, a las fuerzas de la dominación externas e internas les conviene resaltar que la geografía nacional ya no es importante para llevar a cabo de una manera más expedita la apropiación de esos recursos, la privatización del territorio y de sus reservas de agua, la conversión en mercancías de su fauna y de su flora, la apropiación de los saberes indígenas, porque $s i$ la población no tiene conciencia de lo que posee, tampoco comprende lo que pierde.

Si a los habitantes de un país, como Colombia, se les repite todos los días que los recursos naturales no son importantes, difícilmente se organizarán y movilizarán para luchar por defenderlos y tolerarán, por ejemplo, que las fuerzas armadas de Estados Unidos, junto con sus multinacionales, sus espías científicos y sus biopiratas merodeen con plena impunidad a lo largo y ancho de la geografía nacional, que es justamente lo que hoy sucede en nuestro país. A quienes están interesados en legitimar la violación permanente de la soberanía nacional de un país les conviene repetir el estribillo que la idea de soberanía ha sido rebasada por las fuerzas incontenibles de la globalización. Ya Edward Said mostró con lujo de detalles cómo el dominio del espacio se constituye en un componente esencial del imperialismo, al estudiar la expansión europea de finales del siglo XIX y comienzos del siglo XX (Said, 1996).

En este contexto renovado de saqueo y expoliación, la geografía escolar de tipo nacional adquiere importancia, pues debería apuntar al conocimiento del territorio de un país, de sus recursos, de su variedad climática y regional, de sus riquezas, pero también de quiénes y cómo se las apropian y qué consecuencias negativas tiene eso para sus habitantes. El conocimiento de la geografía nacional no solo implica una identidad con el territorio, sino que contribuye a gestar un sentimiento de respeto hacia los ecosistemas al estar enterados de las funciones que estos cumplen como reguladores de las diversas actividades bióticas y antrópicas.

Para hablar nuevamente de Colombia, si no se conoce la importancia que tienen los páramos como reguladores y abastecedores de agua, y los parques y reservas naturales, difícilmente se les 
podrá defender del embate de narcotraficantes y grandes ganaderos, que lo están diezmando de manera acelerada, o el impacto que tiene sobre ellos el uso indiscriminado de la fumigación aérea por parte de Estados Unidos, que cuenta con el respaldo incondicional del gobierno colombiano y las clases dominantes de este país. Porque la geografía nacional debe contribuir a revalorizar la idea de soberanía, pero entendida no como una declaración demagógica, sino como una concepción encaminada a preservar la integridad territorial de un país, a defender sus recursos naturales como patrimonio de todos los habitantes de ese territorio, a impedir que a nombre de las fuerzas de la supuesta modernización se continúe con el saqueo de minerales, bosques y biodiversidad y se extermine con los grupos vernáculos que lo habitan. Si ese conocimiento de lo propio en términos de recursos y de riquezas predominara entre importantes franjas de la población, sería mucho más difícil, para esas fuerzas devastadoras del imperialismo y de sus socios locales, impulsar la apropiación y entrega de la base natural sobre la que se asienta toda comunidad humana, esto es, el territorio y los recursos del suelo y del subsuelo, como están haciéndolo desde hace décadas y como seguirán haciéndolo con la firma de un Tratado de Libre Comercio, que no es ni tratado, ni es comercial, ni mucho menos es libre.

Y la geografía en su dimensión humana y cultural también desempeña un papel de primer orden en el conocimiento de la riqueza desarrollada en un territorio por la interacción entre las sociedades y su medio ambiente. Porque la apropiación del territorio ha moldeado los paisajes y ha configurado formas particulares de cultura, mutuamente dependientes y relacionadas con el manejo de determinados ecosistemas. La geografía escolar debería apuntar a reforzar el conocimiento de la diversidad humana y cultural existente en cierto país, lo cual constituye la riqueza más valiosa, e invaluable, con la que cuenta una nación. Ese conocimiento es clave a la hora de sopesar los efectos transculturizadores de la dominación imperialista, que no solo se apropia de recursos naturales, sino que modifica en sentido negativo la diversidad cultural de un país.
Además, la vulgata de la globalización repite que las naciones ya no tienen razón de ser porque un irreversible proceso de desterritorialización económico, social, político y cultural las ha erosionado. Algunos autores incluso se proclaman como liberados de cualquier atadura territorial y muy campantes sostienen que hoy no tiene ningún sentido pensar los grandes problemas del mundo como fruto de relaciones internacionales, pues no están vinculados con ningún país ante la pretendida desaparición de los centros y las periferias. Un autor nacido en Brasil, pero que se pretende desterritorializado, ha llegado a afirmar que "en lugar de pensar el mundo desde América Latina (como dicen nuestros colegas latinoamericanos), propongo una reorientación de la mirada. Pensemos el mundo en su flujo, y luego hagamos las preguntas pertinentes a nuestra realidad"(Ortiz, 1998: xxi-xxii). Una lectura desprevenida de los acontecimientos de los últimos años indica que no hay nada que se parezca a la tan anunciada desterritorialización, como puede demostrarse con hechos elementales: en ningún lugar del mundo ha sido abolido el pasaporte ni la gente común (con independencia de su origen nacional o social) puede desplazarse libremente; todos los días los Estados nacionales, empezando por Estados Unidos y los miembros de la Unión Europea, hacen más difícil el libre ingreso de los "extranjeros" a su territorio; el Banco Mundial o el Fondo Monetario Internacional no son instituciones transnacionales, sino instrumentos del dominio mundial de Estados Unidos; la represión para detener la protesta contra los procesos de globalización se lleva a cabo por parte de las policías nacionales en un determinado territorio...

Por si hubiera duda del peso que sigue teniendo la territorialidad en el capitalismo actual, recuérdese cómo Estados Unidos ha actuado después de los sucesos del $11 \mathrm{~S}$ para refrendar el papel de sus multinacionales en la lucha mundial por el control de los recursos y por la sumisión de mercados extranjeros, incluyendo aquellos relacionados directamente con la cultura. Resulta significativo que en Irak junto al dominio concedido a las multinacionales estadounidenses del petróleo, del 
gas, de la infraestructura, se ha llegado al extremo de cederle la producción de los textos escolares de los niños iraquíes -antes en manos del Estado- a empresas de Estados Unidos. ¡Qué gran ejemplo de desterritorialización cultural tenemos en el suelo de la antigua Babilonia!

En contra de la supuesta desterritorialización, hay que pensar el mundo desde nuestra realidad, colombiana y latinoamericana, porque no puede hacerse desde una nada inaprensible, desprovista de historia. Por el contrario,"se trata de reapropiarse críticamente de todo lo que sea necesario de lo que ha sido pensado desde siempre y en cualquier punto del 'flujo'. Pero lo que hace la entera diferencia no es tanto el enunciado, sino el lugar de enunciación" (Gruner, 2002:45). La negación de pensar el mundo desde nuestra propia realidad implica plegarse a un universalismo abstracto que no ayuda a entender los problemas concretos de nuestro tiempo, y desechar las formas de dependencia y explotación que sufren las mayorías sociales de nuestro continente o de África, acentuados en los últimos años, en contra de una pretendida homogenización de los seres humanos del planeta tierra, porque es indudable que una parte ínfima del mundo (localizada territorialmente en Estados Unidos, la Unión Europea o Japón, junto con sus émulos de las clases dominantes de todo el orbe) vive mil veces mejor que el resto de los mortales de otros continentes. Paradójicamente, "los desterritorializados son siempre los vencidos; un alto ejecutivo del City Bank en Senegal no está desterritorializado, como no lo estaba un funcionario colonial británico en la India, y como no lo está un miembro de la propia clase dominante senegalesa. Son los trabajadores senegaleses, en todo caso, los que están tan desterritorializados si viven y son explotados en París como si lo hacen en Dakar" (Gruner, 2002: 230).

Por otra parte, la geografía nacional debería ayudar a recuperar las complejas identidades nacionales, desmintiendo las falacias dominantes que hoy sostienen que esas identidades ya no son posibles ni deseables, porque la desterritorialización provocada por la globalización es tan fuerte que las habría suprimido, lo que habría dado origen a identidades supranacionales, o una difusa "ciudadanía mundial”. En contravía, desde la geografía debería recuperarse la importancia del territorio con relación a las culturas, siguiendo la crítica del escritor español Santiago Alba Rico, para quien

es muy fácil reivindicar... la transversalidad, el nomadismo, la deserción, el exilio... en definitiva, el viaje, cuando se tiene un territorio al que volver. Pero cuando te encuentras con decenas de miles de personas encajonadas en... cajas de cerillas, cuando ves claramente el proyecto de negarles un territorio en el que habitar... cuando los ves desprovistos de un espacio, habitando algo así como una figura geométrica sin cielo ni suelo..., cuando uno se enfrenta a un palestino privado de tierra, se comprende que nosotros sí podemos viajar. Pero si podemos viajar es porque tenemos un territorio al que volver. Nos parece que se puede prescindir de eso y reivindicamos el flotamiento por encima de los territorios, de las tradiciones... pero en realidad porque damos por supuesto las nuestras. La identidad nacional hay que dejarla atrás, pero para dejarla atrás hay que tenerla. Como decía Terry Eagleton, solo hay una cosa en este mundo peor que tener una identidad, y es no tener ninguna. Para poder luchar, para poder dejar atrás la identidad, primero hay que forjarse una. Y comenzar por el territorio (Alba Rico, 2005).

\section{Conclusión}

El abandono puro y simple de la historia y la geografía tiene implicaciones desastrosas para el conocimiento de problemas esenciales del mundo social.La renuncia a la historia y a la geografía en los planes de estudio de diversos países ha tenido repercusiones negativas, como en el caso de España, donde se han convertido en "curiosos animales despreciados y en proceso de extinción dentro del sistema educativo" (Hernández, 1998: 17).

Al reivindicar la enseñanza de la historia y la geografía nacionales, es necesario recalcar su importancia en el ámbito educativo. En concordancia con todos los temas analizados en esta ponencia, no sobra recordar que 
En estos momentos la geografía y la historia son una necesidad objetiva en la construcción de nuestras sociedades. Esta afirmación puede parecer sorprendente a estas alturas, pero en realidad es una evidencia empírica. Una sociedad analfabeta en historia y geografía puede resultar altamente inestable, manipulable $y$, en consecuencia, peligrosa. Nuestra sociedad se construye continuamente a partir de una experiencia consciente o inconsciente de civilización. Cortar los lazos que permiten un acceso sistemático y racional a esa experiencia puede significar una concesión a la barbarie (Hernández, 1998: 20).

Por ello, la geografía y la historia son algo más que ortopedias culturales, puesto que son conocimientos imprescindibles, mucho más necesarios que las lenguas extranjeras, la informática o la educación tecnológica, por la sencilla razón de que "la historia y la geografía ayudan a conocer qué es lo que pasa en nuestras sociedades o en las otras, entender qué sucede aquí y en el mundo, y tener elementos de juicio para optar.La geografía y la historia son descodificadores que nos permiten una mejor interpretación de

\section{Bibliografía}

Alba Rico, Santiago. (2005, 17 de mayo) Hoy el marxismo puede y debe ser nacionalista, en Rebelión.

Apple, Michel. (2001). ¿Pueden las pedagogías críticas interrumpir las políticas neoliberales. Opciones Pedagógicas, 24, p. 22.

Banco Mundial.(2003). Aprendizaje permanente en la economía global del conocimiento. Desafíos para los países en desarrollo, Bogotá: Banco Mundial - Alfaomega. Banco Mundial. (1996), Prioridades y estrategias para la educación, Washington.

Bañuelos, Juan. (2004, 18 de junio). Acto de estupidez e ignorancia. En La Jornada.

Caleb, Nelson. (1990, septiembre). Harvard's Hollow Core. The Atlantic Monthly, p. 76, citado por Diana Obregón, Rutas pedagógicas para el estudio de la historia en la educación básica en Bogotá: una aproximación crítica a los lineamientos del Ministerio de Educación sobre el tema. En Rodríguez, José Gregorio. (Ed.). (2004). Rutas Pedagógicas de las múltiples ventanas de información que tenemos abiertas al mundo" (Hernández, 1998: 21).

Porque justamente una de las paradojas más notables de nuestro tiempo radica en que quienes nos cierran las ventanas al mundo, los poderes transnacionales y sus súbditos locales, lo hacen a nombre de una globalización pretendidamente virtuosa, que nos lanzaría, mediante tratados de libre comercio, aperturas económicas indiscriminadas, entrega de los recursos naturales y desaparición de la soberanía nacional, de manera irreversible por un sendero de progreso y felicidad perpetua. Quienes esto pregonan, y ahí estriba la paradoja, son los mismos que en forma consciente han ido eliminando la enseñanza de la historia y la geografía, saberes indispensables no solo para conocernos y saber quiénes somos y de dónde venimos, sino para relacionarnos con el resto del mundo de una manera lúcida e imaginativa, o para decirlo con las palabras de la investigadora argentina Silvia Finocchio, aquellos son saberes que "permiten al alumno conocer diferentes mundos e imaginar otros mundos" (Finocchio, 2003: 232). 기

la historia en la educación básica de Bogotá. Bogotá: Alcaldía Mayor de Bogotá - Universidad Nacional de Colombia, p. 93.

Carretero, Mario. La mirada del otro y la enseñanza de la historia. Extraido desde www.didacticahistoria.com/ ccss/ccss28.htm.

Carretero, Mario y Voss, James F. (Comp.). (2004). ¿Forjar patriotas o educar cosmopolitas? El pasado y el presente de la historia escolar en un mundo global. Aprender y pensar la historia. Buenos Aires: Amorrortu Editores, p. 86.

Duclos, Denis. (2002). Societé-monde, le temps des ruptures. París: La Découverte.

Ferro, Marc. (1970). La gran guerra. Madrid: Alianza Editorial.

Finocchio, Silvia. (2003, septiembre). Entrevista. En Reseñas de Enseñanza de la Historia. Asociación de Profesores de Enseñanza de la Historia de Universidades Nacionales, Córdoba, N.o 1, p. 232. 
Finkelstein, Norman G. (2002). La industria del holocausto. Reflexiones sobre la explotación del sufrimiento judio, Madrid: Siglo XXI Editores.

Florescano, Enrique. Para qué estudiar y enseñar la historia. Extraido desde www.geocities.com/revista_conciencia/florescano.html.

Fontana, Joseph. (2003). ¿Para qué sirve la historia en un tiempo de crisis? Bogotá: Ediciones Pensamiento Crítico.

Fontana, Joseph. El nacionalismo está aquí para quedarse. El Viejo Topo, 102, p. 31.

Fuentes Ortega, Juan B. y Callejo Herranz, María José. En torno a la idea de "sociedad del conocimiento": Crítica (filosófico-política) a la LOU, a su contexto y a sus críticos. Extraido desde www.filosofia.net/ materiales/num/num17/Critilou.htm

Giroux, H. (2002). Pedagogía pública y política de la resistencia: notas para una teoría crítica de la lucha educativa. Opciones Pedagógicas, 25, p. 48.

Gruner, Eduardo. (2002). El fin de las pequeñas historias. De los estudios culturales al retorno (imposible) de lo trágico. Buenos Aires: Paidós.

Harvey, David. (2004). El nuevo imperialismo. Barcelona: Akal.

Harvey, David. (1995). The Condition of Postmodernity. Cambridge: Blackwell Publishing.

Harvey, David. El 'nuevo' imperialismo: sobre reajustes espacio-temporales y acumulación mediante desposesión (I). Extraido desde www.viento delsur.info/ articulos.web/textos/index.php?x=195/196

Hernández, F. X. (1998, agosto). La enseñanza de las ciencias sociales. Balance y perspectivas. Educación y Cultura, 47, p. 17, 22.

Hosbawm, Eric. (1998). Dentro y fuera de la historia. En Sobre la historia. Barcelona: Editorial Crítica.

Hosbawm, Eric. (1991). Naciones y nacionalismo desde 1870, Barcelona: Editorial Crítica; Nación, Estado, etnicidad y religión. Transformaciones de la identidad; ¿Qué es un conflicto étnico?, publicados en Vega Cantor, Renán. (ed.). (1998). Marx y el siglo XXI. Hacia un marxismo ecológico y crítico del progreso.

Ianni, Octavio. (1995, septiembre). Estado-nación y globalización. El Cotidiano. Revista de la Realidad Mexiana Actual, 71.

Jaulin, Robert. (1980). La des-civilización. Teoría y práctica del etnocidio. México: Nueva Imagen.
Lamoneda, Mireya. (1998). La historia estatal a partir de la modernización educativa. En: Javier Pérez Siller y Verena Radkau García (coord.). Identidad en el imaginario nacional: reescritura y enseñanza de la historia. México, D.F.: Instituto de Ciencias Sociales y Humanidades, BUAP, Puebla, El Colegio San Luis, AC, e Instituto Georg-Eckert.

Larson, Brooke. (2002). Indígenas, elites y estado en la conformación de las repúblicas andinas. Lima: Instituto de Estudios Peruanos.

Ministerio de Educación Nacional. Lineamientos curriculares para el área de Ciencias Sociales. Bogotá: Editorial Magisterio, s.f.

Mires, Fernando. (2000). Teoría política del nuevo capitalismo o el discurso de la globalización, Caracas: Editorial Nueva Sociedad, p. 47.

Múnera, Alfonso. (2005). Fronteras imaginadas. La construcción de las razas y de la geografía en el siglo XIX colombiano. Bogotá: Planeta.

Ortiz, Renato. (1998). Otro territorio. Ensayos sobre el mundo contemporáneo. Bogotá: Ediciones Convenio Andrés Bello.

Rebellato, José Luis. La globalización y su impacto educativo-cultural. El nuevo horizonte posible. Extraido desde www.franciscanos.net/teologos/mfal/ rebelato.htm

Sánchez Quintanar, Andrea. (1998). Identidad y conciencia en la enseñanza de la historia. En Javier Pérez Siller y Verena Radkau García (coordinadores). Identidad en el imaginario nacional: reescritura $y$ enseñanza de la historia. México, D.F.: Instituto de Ciencias Sociales y Humanidades, BUAP, Puebla, El Colegio San Luis, AC, e Instituto Georg-Eckert.

Said, Edward. (1996). Cultura e imperialismo. Barcelona: Anagrama.

Saxe-Fernández, Eduardo y Brugger Burgeois, Christian. (1999). La democracia en el globalismo neoliberal latinoamericano. En: Saxe-Fernández, Jhon. (Coord.). Globalización: crítica a un paradigma. México: Plaza y Janes, p. 309.

Vega Cantor, Renán. (Ed.). (1997). Subcomandante Marcos. El neoliberalismo: enemigo de la tierra, de la historia y de la cultura. En: Marx y el siglo XXI. Una defensa de la historia y el socialismo. Bogotá: Ediciones Pensamiento Crítico. 